\title{
Daily Triglyceride Output Volume as an Early Predictor for Chyle Leak Following Pancreaticoduodenectomy
}

\author{
TARO SAKAMOTO $^{1}$, NORIMITSU OKUI ${ }^{1}$, FUMITAKE SUZUKI ${ }^{1}$, RYOGA HAMURA ${ }^{2}$, \\ YOSHIHIRO SHIRAI ${ }^{2}$, KOICHIRO HARUKI ${ }^{2}$, KENEI FURUKAWA ${ }^{2}$ and TORU IKEGAMI ${ }^{2}$ \\ ${ }^{1}$ Division of Digestive Surgery, Saku Central Hospital Advanced Care Center, Saku, Japan; \\ ${ }^{2}$ Division of Digestive Surgery, Department of Surgery, The Jikei University School of Medicine, Tokyo, Japan
}

\begin{abstract}
Background/Aim: Useful prophylaxes of chyle leak (CL) after pancreatic surgery have not been established. The aim of the study was to identify an early clinical predictor for CL. Patients and Methods: Fifty-five patients who underwent subtotal stomach preserved pancreaticoduodenectomy (SSPPD) were included. Clinical factors associated with postoperative CL were evaluated. Results: Eleven patients (20\%) developed a CL after SSPPD. Shorter operative time, absent pancreatic fistula, and triglyceride output volume at postoperative day (POD) two were independent risk factors for $C L$. The receiver operating characteristics curve of the daily triglyceride output volume at POD two indicated a cutoff point of $177 \mathrm{mg}$ ( $A U C=0.782$; $p=0.004 ; 95 \%$ CI=0.6390.925). CL was significantly associated with prolonged postoperative hospital stay in patients who did not develop a pancreatic fistula $(p=0.003)$. Conclusion: Daily triglyceride output volume of $>177 \mathrm{mg}$ at POD two may be a predictor of CL following pancreaticoduodenectomy.
\end{abstract}

Postoperative chyle leak (CL) is not a rare complication after pancreatic surgery, with an incidence up to $16 \%$ (1-3), and causes prolonged postoperative hospital stay (2). The latter is a negative factor for survival, especially in patients with pancreatic cancer, because of the resulting delay in initiation of adjuvant chemotherapy $(4,5)$.

Previous studies have suggested various risk factors for postoperative CL after pancreatic surgery, such as female gender (1), distal pancreatectomy (2), retroperitoneal tumor invasion (6), number of lymph nodes harvested (7), early

This article is freely accessible online.

Correspondence to: Taro Sakamoto, MD, Ph.D., Division of Digestive Surgery, Saku Central Hospital Advanced Care Center, 3400-28 Nakagomi, Saku, Nagano, 385-0051, Japan. Tel: +81 267628181, Fax: +81 267887354, e-mail: sakamo634@gmail.com

Key Words: Chyle leak, triglycerides, pancreaticoduodenectomy. enteral feeding $(6,8)$, and pancreatic fistula (2). A review article concluded that $\mathrm{CL}$ was mainly predicted by the extent of lymphadenectomy and lymphatic tissue dissection (9). However, there are few studies which suggest a clinical predictor for postoperative CL. Kim et al. reported that drainage fluid volume $>335 \mathrm{ml}$ by the fourth postoperative day was a useful and simple predictor for postoperative CL (10). However, drainage fluid volume is influenced by various factors such as intra-abdominal inflammation, liver function, poor nutritional state, and chronic heart diseases. Similarly, triglyceride concentration also depends on the drainage fluid volume. Hence, these factors might not be the best predictors for CL. We hypothesized that the total amount of triglyceride output volume may reflect the true leakage volume more accurately compared to the fluid volume or the triglyceride concentration in the drainage fluid. Moreover, we hypothesized that triglyceride output volume may reflect late CL even if measured in the early postoperative period.

Thus, the aim of the study was to determine whether triglyceride volume in the drainage fluid, measured before postoperative resumption of oral intake, could be a predictor of postoperative CL.

\section{Patients and Methods}

Patient cohort. This study was approved by the Internal Review Board (IRB) of the Saku Central Hospital Advanced Care Center (IRB number R201802-01) and followed the tenets set by the Declaration of Helsinki. Between August 2018 and June 2020, the medical records of all the patients who underwent subtotal stomach preserved pancreaticoduodenectomy (SSPPD) at the Saku Central Hospital Advanced Care Center were reviewed. There were no exclusion criteria.

Surgical procedure. All surgeries were performed by one of three surgeons operating in the Saku Central Hospital Advanced Care Center., all of whom are authors of current article (T.S., N.O., F.S.). Following a mid-line laparotomy, the para-aortic lymph node area was sampled and examined by intraoperative frozen-section for all patients regardless of the preoperative tumor diagnosis, with an 
exception of one patient with chronic pancreatitis. Patients underwent palliative surgery if the para-aortic lymph nodes were positive by intraoperative pathological diagnosis. Lymph nodes were routinely dissected around the hepatoduodenal ligament, common hepatic artery, and superior mesenteric artery for all patients using unipolar cutting cautery or Hermonic ${ }^{\circledR}$ vessel-sealing device (Ethicon, Tokyo, Japan). The pancreatic head and uncinate process nerve plexuses were dissected using the same device and plexuses of the superior mesenteric and celiac artery were preserved circumferentially. The mesentery was dissected along with the second jejunal artery and jejunal vein. The first jejunal artery was ligated at its base. Based on our institutional policy, end-to-side pancreatojejunostomy with an incomplete external stent, end-to-side hepaticojejunostomy with or without ductal stent, side-to-side gastrojejunostomy, and Braun anastomosis were routinely performed for reconstruction. From August 2018 to December 2019, we provided early enteral nutrition to postoperative patients via a feeding jejunostomy tube, which was placed in the upper jejunum. Two drains were routinely placed, one anterior to the pancreatojejunostomy site, and another posterior to the hepaticojejunostomy site.

Postoperative management. Following the nasogastric tube removal on postoperative day (POD) one, only clear liquids were allowed and oral food intake, which contained fat, was started on POD three if tolerated by the patient. From August 2018 to December 2019, patients received enteral nutrition starting POD three with continuous $20 \mathrm{ml} / \mathrm{h}$ low fat elemental diet $\left(\right.$ ELENTAL $^{\circledR}$, EA Pharma, Tokyo, Japan) until they were able to tolerate sufficient oral intake. All patients had their drain amylase and triglyceride levels measured at PODs one and three. Drains were removed on POD three if there was no pancreatic fistula or bile leakage. Pancreatic fistula was treated with only continuous drainage therapy. No patients received octreotide.

Identification and management chyle leak. $\mathrm{CL}$ was defined as an output of any milky discharge from patients' drains or drain sites on or after POD three with a triglyceride content $\geq 110 \mathrm{mg} / \mathrm{dl}$, in accordance with the International Study Group of Pancreatic Surgery (ISGPS) criteria (11). Once diagnosed, patients were treated conservatively with seven days of diet-withholding. If the fluid volume was less than $50 \mathrm{ml}$ at the time of the diagnosis, dietwithholding therapy was discontinued once the milky discharge disappeared. If CL recurred after restarting oral diet, additional diet-withholding with total parenteral nutrition was adopted until the CL resolved.

Dairy triglyceride output volume at POD two. Since CL occurs following oral intake, it is important to seek an early clinical warning sign which can be identified before the postoperative resumption of oral intake. The total amount of the drainage triglyceride volume of POD two was determined as the sum of all drain output amounts which were calculated by multiplying the 24hour (from 9 a.m. on POD two to 9 a.m. on POD three) fluid volume with the corresponding concentration.

Statistical analysis. Summary statistics were expressed using median and range. The association of clinical factors with CL was analyzed by univariate analysis. Continuous data sets were analyzed by the nonparametric Mann-Whitney $U$-test and discontinuous data
Table I. Patient demographics and pathologic features $(N=55)$.

Characteristics

Age (years), median (range)

$73(52-86)$

Gender, male

$38(69)$

Pathologic diagnosis

Pancreatic cancer

$25(45)$

Intraductal papillary mucinous adenoma $3(5)$

Pancreatic neuroendocrine neoplasm 4 (7)

Pancreatitis

$4(7)$
$1(2)$

Bile duct cancer

$11(20)$

Ampulla carcinoma

$3(5)$

Duodenal carcinoma

$6(11)$

Duodenal neuroendocrine neoplasm

$2(4)$

Data are expressed as n (\%) unless otherwise specified.

sets were analyzed with the Chi squared test. Factors found to be significant on univariate analysis were subjected to multivariate analysis using a logistic regression model. The receiver operating characteristics (ROC) curve of the daily triglyceride drainage volume on POD two was used to predict CL. Mann-Whitney $U$-test was used for comparison of the postoperative duration of hospital stay between the patients with, and without CL. Values of $p<0.05$ were considered statistically significant. These analyses were conducted using IBM $^{\circledR}$ SPSS statistics version 25.0 (IBM Japan, Tokyo, Japan).

\section{Results}

Patient characteristics. A total of 55 consecutive patients who underwent SSPPD were analyzed in the study. The patient demographics and pathological characteristics of our cohort are summarized in Table I. Median age was 73 years (range $=52-86$ years) and 38 of them $(69 \%)$ were males. The median body mass index (BMI) was $22.2 \mathrm{~kg} / \mathrm{m}^{2}$ (range $=16.0$ $28.6 \mathrm{~kg} / \mathrm{m}^{2}$ ). The pathologic diagnosis was pancreatic carcinoma in $25(45 \%)$, periampullary carcinoma in $20(36 \%)$, neuroendocrine neoplasm in $6(11 \%)$, pancreatic intraductal mucinous neoplasm in $3(5 \%)$, and chronic pancreatitis in 1 patient (2\%). The median operative time was $494 \mathrm{~min}$ (range $=330-756 \mathrm{~min}$ ) and the median intraoperative blood loss was $521 \mathrm{ml}$ (range $=100-3,100 \mathrm{ml}$ ). The operators were boardcertified expert surgeons in $22(40 \%)$ and training surgeons in the rest of cases. The median daily fluid volume and triglyceride concentrations in the fluid by POD two were 290 $\mathrm{ml}($ range $=68-1,680 \mathrm{ml})$ and $34 \mathrm{mg} / \mathrm{dl}($ range= $8-493 \mathrm{mg} / \mathrm{dl})$, respectively. The median triglyceride output volume at POD two was $127.5 \mathrm{mg}$ (range=27.5-872.4 mg). Of the 55 patients, grade $\mathrm{B} / \mathrm{C}$ pancreatic fistula was present in $23(42 \%)$; grade $\mathrm{B}$ in $20(36 \%)$ patients; and grade $\mathrm{C}$ in $3(5 \%)$. One patient (2\%) died because of deterioration of pre-existing interstitial pneumonia. The median postoperative hospital stay was 26 days (range $=15-101$ days). 
Sakamoto et al: Triglyceride as a Predictor of Chyle Leak After Pancreaticoduodenectomy

Table II. Variables associated with postoperative chyle leak after SSPPD.

\begin{tabular}{|c|c|c|c|}
\hline Variables & Chyle leak $(n=11)$ & No chyle leak $(\mathrm{N}=44)$ & $p$-Value \\
\hline Age (years)* & $73(54-84)$ & $73(52-86)$ & 0.7 \\
\hline Gender, males & $8(73)$ & $30(68)$ & 0.94 \\
\hline $\mathrm{BMI}\left(\mathrm{kg} / \mathrm{m}^{2}\right)^{*}$ & $20.9(16.0-23.8)$ & $22.8(16.6-28.6)$ & 0.09 \\
\hline Operative time $(\mathrm{min})^{*}$ & $449(363-539)$ & $533(330-756)$ & 0.007 \\
\hline Intraoperative blood loss $(\mathrm{ml})^{*}$ & $498(100-1,400)$ & $721(100-3,100)$ & 0.36 \\
\hline Operator, certified expert surgeons $* *$ & $2(18)$ & $20(45)$ & 0.19 \\
\hline Pancreatic fistula, ISGPF grade B/C & $1(9)$ & $22(50)$ & 0.034 \\
\hline Postoperative initial oral diet intake (days)* & $3(3-6)$ & $4(3-9)$ & 0.19 \\
\hline Enteral nutritional support & $5(45)$ & $29(66)$ & 0.37 \\
\hline Fluid volume of POD $2(\mathrm{ml})^{*}$ & $330(110-1290)$ & $262(68-1680)$ & 0.14 \\
\hline Triglyceride concentration in the fluid of POD $2(\mathrm{mg} / \mathrm{dl})^{*}$ & $64(22-104)$ & $38(13-493)$ & 0.08 \\
\hline Daily triglyceride output volume of POD $2(\mathrm{mg})^{*}$ & $186(70-511)$ & $98(30-872)$ & 0.004 \\
\hline
\end{tabular}

Data are expressed as n (\%) unless otherwise specified; *Values are median (range). **Certified by the Japanese Society of Hapato-Biliary-Pancreatic Surgery. SSPPD: Subtotal stomach-preserving pancreaticoduodenectomy; BMI: body mas index; ISGPF: international study group on pancreatic fistula; POD: postoperative days.

Incidence and risk factors for chyle leak. CL occurred in 11 patients (20\%) after SSPPD. All patients diagnosed as CL, characterized by obvious milky discharge from their drainage tubes or drain site, were identified between POD 5 and POD 13. The median time to CL presentation following the postoperative resumption of oral intake was four days (range $=2-7$ days) and the median diet-withholding duration for the resolution of CL was ten days (range $=2$ to 20 days). The clinical characteristics of patients with and without CL are summarized in Table II. On univariate analysis, shorter operating time $(p=0.007)$, absent grade $\mathrm{B} / \mathrm{C}$ pancreatic fistula $(p=0.034)$, and daily triglyceride output volume at POD two $(p=0.004)$ were significantly associated with an increased incidence of postoperative CL. On multivariate logistic regression analysis, all these factors remained independently significant risk factors for the development of CL (Table III).

Cut-off points of the daily triglyceride output volume. All instances of CL occurred after the resumption of oral diet postoperatively, and all were resolved by diet-withholding. We, therefore, hypothesized that CL could be prevented by deferring oral intake if the daily triglyceride output volume at POD two was high (we routinely allowed oral diet intake on POD three, as noted above). Based on the ROC curve, we investigated the cut-off point for a triglyceride output volume of $177 \mathrm{mg}$ with an area under the curve of $0.782(95 \%$ $\mathrm{CI}=0.639-0.925$ ) (Figure 1). A daily triglyceride output volume of $>177 \mathrm{mg}$ indicated suspicion of CL (sensitivity $72.7 \%$, specificity $72.7 \%$ ).

Association between postoperative hospital stay and complications. The association between postoperative
Table III. Multivariate analysis of factors associated with postoperative chyle leak after SSPPD.

\begin{tabular}{|c|c|c|}
\hline & OR $(95 \% \mathrm{CI})$ & $p$-Value \\
\hline Operative time & $0.05(0.004-0.539)$ & 0.014 \\
\hline Pancreatic fistula, ISGPF grade B/C & $0.06(0.003-0.746)$ & 0.03 \\
\hline $\begin{array}{l}\text { Daily triglyceride output volume } \\
\text { of POD } 2>177 \mathrm{mg}\end{array}$ & $22.4(2.2-232.7)$ & 0.009 \\
\hline
\end{tabular}

SSPPD: Subtotal stomach-preserving pancreaticoduodenectomy; OR: odds ratio; CI: confidence intervals; ISGPF: international study group on pancreatic fistula; POD: postoperative days.

hospital stay and complications is summarized in Table IV. For all 55 patients, CL was not associated with a longer postoperative hospital stay $(p=0.83)$, but a pancreatic fistula was $(p<0.001)$. We then analyzed the association between development of CL and increased postoperative hospital stay for patients who did not develop a pancreatic fistula $(n=32)$ : postoperative hospital stay in patients with a CL was found to be significantly longer than those without a CL $(p=0.003)$.

\section{Discussion}

The incidence of CL after SSPPD in this study was $20 \%$. This was higher than most previous studies which reported an incidence of $1.8 \%-16.0 \%(1,3,6-8,10)$. This dissimilarity could be explained by our definition of CL which included any volume of milky discharge with a triglyceride content $\geq 110 \mathrm{mg} / \mathrm{dl}$. In contrast, most previous studies which reported an incidence lower than $10 \%$, included a criteria of daily fluid volume $>100 \mathrm{ml}$ or up to $600 \mathrm{ml}(6-8)$. A recent large series, whose definition was the same as our study, reported the 


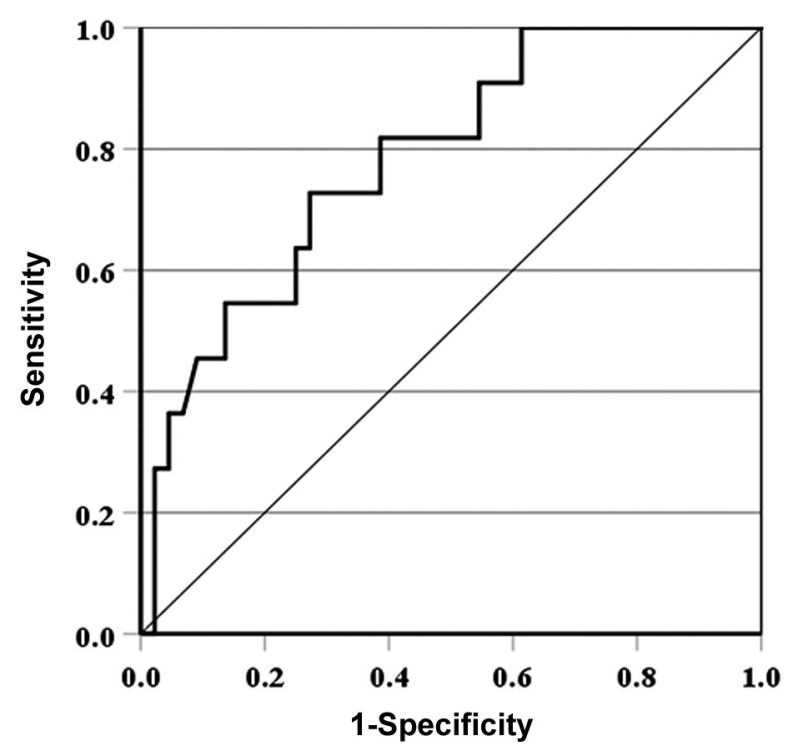

Figure 1. ROC curve of daily triglyceride output volume of POD 2. The optimal cut-off levels for the daily triglyceride output volume of POD 2 was $177 \mathrm{mg}$, with the area under the curve was 0.782 (95\% $C I=0.639-0.925, p=0.004)$.

presence of a CL in $12.5 \%$ of patients after pancreaticoduodenectomy (PD) (2). Therefore, CL cannot be thought of as a rare complication after pancreatic surgery, especially if the definition is broader.

There are no randomized clinical trials that recommend one surgical procedure over another, nor any clinical treatment to prevent postoperative CL. Thus, it is important to look for clinical warning signs for a CL. Aoki et al. reported on the effectiveness of intraoperative "Milk Test" to prevent CL in their prospective patient cohort (12). They attempted to confirm injury to lymphatic vessels intraoperatively by administration of milk to the upper jejunum. This method is thought to be reasonable for preventing $\mathrm{CL}$, but did not achieve statistically significant improvements when analyzed. This study is the first report, to the best of our knowledge, to indicate a predictor for postoperative CL by measuring the total amount of triglyceride output. We hypothesized that the triglyceride output volume reflects the true leakage volume more accurately than the drainage fluid volume or its triglyceride concentration. In this study, the daily triglyceride output volume by POD two was significantly associated with the development of postoperative CL, but the fluid volume and triglyceride concentration in the fluid at POD two did not reach significance on univariate analysis. These results follow the essence of our hypothesis that fluid volume and triglyceride concentration depends on various factors. The ROC curve for triglyceride output volume by POD two indicated that a cut-off of $>177 \mathrm{mg}$ could be a predictor for a CL with a sensitivity of $72.7 \%$ and a specificity of $72.7 \%$.
Table IV. Variables associated with postoperative hospital stay after SSPPD

\begin{tabular}{lccc}
\hline Variables & $\mathrm{N}$ & $\begin{array}{c}\text { Postoperative } \\
\text { hospital stay } \\
\text { (days)* }\end{array}$ & $p$-Value \\
& & & \\
\hline Chyle leak (whole patients) & & $30(15-101)$ & 0.83 \\
$\quad$ Absent & 44 & $29(18-62)$ & $<0.001$ \\
$\quad \begin{array}{l}\text { Present } \\
\text { Pancreatic fistula (PF) }\end{array}$ & 11 & & \\
$\quad$ Absent & 32 & $22(15-62)$ & \\
$\quad$ Present & 23 & $40(23-101)$ & 0.003 \\
Chyle leak (excluded PF) & & & \\
$\quad$ Absent & 22 & $19(15-33)$ & \\
Present & 10 & $29(18-62)$ & \\
\hline
\end{tabular}

*Values are median (range). SSPPD: Subtotal stomach-preserving pancreaticoduodenectomy.

Since all CLs occurred after the initiation of postoperative oral diet and were resolved by diet-withholding, this predictor may be useful if CLs can be predicted before the initiation of oral intake. In this study, the median time to CL presentation following the postoperative resumption of oral intake was four days, and the median diet-withholding duration for the resolution of CL was ten days. Therefore, delayed imitation of postoperative initial intake may possibly prevent $\mathrm{CL}$ in patients who satisfy our identified cut-off point. Moreover, this preventive measure may decrease the risk of prolonged hospital stay. Based on these results, however, nearly $30 \%$ of the patients who had a POD2 value $>177 \mathrm{mg}$ did not develop CL. Navez et al. (13) reported that early postoperative oral intake after PD was significantly associated with lower rate of severe postoperative morbidity and shorter hospital stay. Thus, further studies are expected to exclude these false-positive patients or to minimalize the duration of prophylactic dietwithholding.

There might be some debate as to whether triglyceride output measurement is an appropriate method when measured in the early postoperative and fasting state. Clinically, milky discharge is often visualized a day or two after the initiation of oral diet and remains for at least a day if therapeutic diet-withholding is initiated. This study also noted a median of four days between the initiation of oral diet and a diagnosis of CL. These clinical features indicate that some discrepancy exists between the intestinal absorption of triglyceride and the chylomicron delivery to the lymphatic vessels. Aoki et al. reported that lymphatic flow in the cisterna chili was very slow: $<1 \mathrm{ml} / \mathrm{min}$ in the fasting state compared to $225 \mathrm{ml} / \mathrm{min}$ after ingestion of a fatty meal (12). Therefore, we hypothesize that triglyceride output by POD two reflects the triglyceride absorption of preoperative oral diet intake and our criteria can be feasible. 
Similar to previous reports $(14,15)$, we found that pancreatic fistula was significantly associated with increased postoperative hospital stay, though CL was not associated with the latter when analyzing the whole population, possibly due to the stronger effect of pancreatic fistula development over increased postoperative stay. However, CL was noted to be a significant factor associated with prolonged postoperative hospital stay in patients who did not develop a pancreatic fistula. Thus, our threshold may need to be adjusted to that limited subset of patients.

There is no consensus on whether postoperative pancreatic fistula is associated with CL $(2,10)$. This study revealed a significant association between $\mathrm{CL}$ and absent grade $\mathrm{B} / \mathrm{C}$ pancreatic fistulas. The cisterna chyli is located anterior to the superior lumbar vertebrae and lies at the same level as that of the pancreatic head and neck $(16,17)$. Thus, it is understandable that CL occurs after pancreaticoduodenectomy, including SSPPD, due to the traumatic nature of the procedure. We hypothesize that local inflammation around the pancreatojejunostomy site, induced by a pancreatic fistula, accelerates injured lymphatic vessel closure. More studies will be required to confirm this hypothesis, since currently there are no reports investigating the pathological relationship between pancreatic fistulas and injured lymphatic vessel closure.

The reason for the association between CL and shorter operative time is unclear. However, Kim et al. (10) reported the same result in their univariate analysis and hypothesized that lesser surrounding inflammation might preserve the lymphatic inflow, and that CL might occur easily if lymphatic ducts were injured. Operative time is also influenced by various factors such as tumor T-stage, BMI, adhesions from past operations, operator skill and technique, etc.

A major limitation of our study is that it was retrospective, single-institution study that examined a small number of patients. In order to gather more definitive evidence, further studies are needed.

In conclusion, daily triglyceride output volume $>177 \mathrm{mg}$ by POD two indicates a possibility of developing postoperative CL after SSPPD. Further studies are needed, which assess whether the delayed administration of postoperative initial oral intake can prevent CL in patients who meet that cut-off point.

\section{Conflicts of Interest}

All Authors disclose no conflicts of interest.

\section{Authors' Contributions}

TI, KF and $\mathrm{KH}$ were involved with design of this study and manuscript. Data were collected by NO and FS and analyzed by RH, YS and KH. TI and KH proofread the manuscript. All Authors have read and approved the final version of the edited manuscript.

\section{Acknowledgements}

The Authors would like to thank Editage [http://www.editage.com] for editing and reviewing this manuscript for English language.

\section{References}

1 van der Gaag NA, Verhaar AC, Haverkort EB, Busch OR, van Gulik TM and Gouma DJ: Chylous ascites after pancreaticoduodenectomy: introduction of a grading system. J Am Coll Surg 207(5): 751-757, 2008. PMID:18954789. DOI:10.1016/j.jamcoll surg.2008.07.007

2 Strobel O, Brangs S, Hinz U, Pausch T, Hüttner FJ, Diener MK, Schneider L, Hackert T and Büchler MW: Incidence, risk factors and clinical implications of chyle leak after pancreatic surgery. $\mathrm{Br} \quad \mathrm{J}$ Surg 104(1): 108-117, 2017. PMID:27763684. DOI: $10.1002 /$ bjs. 10316

3 Abu Hilal M, Layfield DM, Di Fabio F, Arregui-Fresneda I, Panagiotopoulou IG, Armstrong TH, Pearce NW and Johnson CD: Postoperative chyle leak after major pancreatic resections in patients who receive enteral feed: risk factors and management options. World J Surg 37(12): 2918-2926, 2013. PMID:24101011. DOI:10.1007/s00268-013-2171-x

4 Murakami Y, Uemura K, Sudo T, Hashimoto Y, Kondo N, Nakagawa N, Sasaki H and Sueda T: Early initiation of adjuvant chemotherapy improves survival of patients with pancreatic carcinoma after surgical resection. Cancer Chemother Pharmacol 71(2): 419-429, 2013. PMID:23178955. DOI:10.1007/s00280012-2029-1

5 Kim HW, Lee JC, Lee J, Kim JW, Kim J and Hwang JH: Early versus delayed initiation of adjuvant treatment for pancreatic cancer. PLoS One 12(3): e0173960, 2017. PMID:28301556. DOI: 10.1371/journal.pone.0173960

6 Kuboki S, Shimizu H, Yoshidome H, Ohtsuka M, Kato A, Yoshitomi H, Furukawa K and Miyazaki M: Chylous ascites after hepatopancreatobiliary surgery. Br J Surg 100(4): 522-527, 2013. PMID:23288577. DOI: $10.1002 / b j s .9013$

7 Assumpcao L, Cameron JL, Wolfgang CL, Edil B, Choti MA, Herman JM, Geschwind JF, Hong K, Georgiades C, Schulick $\mathrm{RD}$ and Pawlik TM: Incidence and management of chyle leaks following pancreatic resection: a high volume single-center institutional experience. J Gastrointest Surg 12(11): 1915-1923, 2008. PMID:18685899. DOI:10.1007/s11605-008-0619-3

8 Malik HZ, Crozier J, Murray L and Carter R: Chyle leakage and early enteral feeding following pancreatico-duodenectomy: management options. Dig Surg 24(6): 418-422, 2007. PMID:17855780. DOI:10.1159/000108324

9 Weniger M, D'Haese JG, Angele MK, Kleespies A, Werner J and Hartwig W: Treatment options for chylous ascites after major abdominal surgery: a systematic review. Am J Surg 211(1): 206-213, 2016. PMID:26117431. DOI:10.1016/j.amj surg.2015.04.012

10 Kim JK, Park JS, Hwang HK, Shin HW and Yoon DS: Drainage volume after pancreaticoduodenectomy is a warning sign of chyle leakage that inversely correlates with a diagnosis of pancreatic fistula. World J Surg 37(4): 854-862, 2013. PMID:23389668. DOI: $10.1007 / \mathrm{s} 00268-013-1919-7$

11 Besselink MG, van Rijssen LB, Bassi C, Dervenis C, Montorsi M, Adham M, Asbun HJ, Bockhorn M, Strobel O, Büchler MW, Busch OR, Charnley RM, Conlon KC, Fernández-Cruz L, 
Fingerhut A, Friess H, Izbicki JR, Lillemoe KD, Neoptolemos JP, Sarr MG, Shrikhande SV, Sitarz R, Vollmer CM, Yeo CJ, Hartwig W, Wolfgang CL, Gouma DJ and International Study Group on Pancreatic Surgery. Definition and classification of chyle leak after pancreatic operation: A consensus statement by the International Study Group on Pancreatic Surgery. Surgery 161(2): 365-372, 2017. PMID:27692778. DOI:10.1016/j.surg.2016.06.058

12 Aoki H, Takakura N, Shiozaki S and Matsukawa H: Milk-based test as a preventive method for chylous ascites following pancreatic resection. Dig Surg 27(5): 427-432, 2010. PMID:20975273. DOI:10.1159/000320692

13 Navez J, Hubert C, Dokmak S, Frick De La Maza I, Tabchouri N, Benoit O, Hermand H, Zech F, Gigot JF and Sauvanet A: Early versus late oral refeeding after pancreaticoduodenectomy for malignancy: a comparative Belgian-French study in two Tertiary Centers. J Gastrointest Surg 24(7): 1597-1604, 2020. PMID:31325133. DOI:10.1007/s11605-019-04316-8

14 Lin JW, Cameron JL, Yeo CJ, Riall TS and Lillemoe KD: Risk factors and outcomes in postpancreaticoduodenectomy pancreaticocutaneous fistula. J Gastrointest Surg 8(8): 951-959, 2004. PMID:15585382. DOI:10.1016/j.gassur.2004.09.044
15 Akgul O, Merath K, Mehta R, Hyer JM, Chakedis J, Wiemann B, Johnson M, Paredes A, Dillhoff M, Cloyd J and Pawlik TM: Postoperative pancreatic fistula following pancreaticoduodenectomy-stratification of patient risk. J Gastrointest Surg 23(9): 1817-1824, 2019. PMID:30478529. DOI:10.1007/s11605018-4045-x

16 Evans JG, Spiess PE, Kamat AM, Wood CG, Hernandez M, Pettaway CA, Dinney CP and Pisters LL: Chylous ascites after post-chemotherapy retroperitoneal lymph node dissection: review of the M. D. Anderson experience. J Urol 176(4 Pt 1): 1463-1467, 2006. PMID:16952661. DOI:10.1016/j.juro.2006.06.016

17 Loukas M, Wartmann CT, Louis RG Jr, Tubbs RS, Salter EG, Gupta AA and Curry B: Cisterna chyli: a detailed anatomic investigation. Clin Anat 20(6): 683-688, 2007. PMID:17415746. DOI:10.1002/ca.20485

Received January 13, 2021

Revised January 30, 2021

Accepted February 1, 2021 